\title{
Women, mental health and the family
}

\author{
Henrikje Klasen, Helen Crimlisk and Sarah Welch
}

This edition of the Psychiatric Bulletin contains a series of articles looking at issues surrounding women and psychiatry. The Royal College of Psychiatrists has recently set up a special interest group on this subject, and with public concern growing about topics such as single sex wards, gender-sensitive services, the progression of women's careers and part-time work opportunities, interest seems likely to continue to grow. Conferences organised by trainee women psychiatrists with women and mental health as a general theme have been held at the Institute of Psychiatry, London, for the last five years, covering issues such as the law and community provision. The fifth conference took as its theme the family, influenced in part by the United Nations Year of the Family in 1994.

The first topic of the conference was to review critically the concept of 'family'. Family structures in the UK are becoming increasingly diverse. Single-parent families are common. and especially in a multicultural context, concepts of families can vary from matrifocal to extended families including not only several generations but also step-parents, half-siblings or adopted children living together. In addition. there are new family forms to be considered. Homosexual couples or groups of friends may live together and raise children. The concept of 'dysfunctional families' plays a major role in the theoretical framework, assessment and treatment of psychiatric disorders. However, culturally determined preconceptions may influence our view of normality (Eisenberg, 1988) and can affect diagnostic as well as therapeutic work.

The conference also considered how illness, especially mental illness, can influence the lives of women throughout the life cycle (Subotsky, 1991). As girls they may experience physical or sexual abuse or inadequate care, possibly linked to substance misuse or mental illness in their families. In adulthood, choices have to be made between career and family which can lead to feelings of loss and helplessness whatever decision is made (Duxbury \& Higgins, 1991). In mothers, guilt feelings often occur when children develop mental health or behavioural problems.
In later life, women are more likely than men to care for mentally or chronically ill family members. The burden of care can lead potentially to mental health problems for the carers. Equally. women may be affected by isolation, stigma. blame, guilt and secrecy often attached to mental health problems in the family.

Finally, women's own mental or physical illhealth can have an effect on family function. Their own depression, psychotic illnesses, substance misuse or physical problems can influence the development of their children as well as family function in general. It often seems impossible to identify the origin of mental health problems in families, and vicious circles develop with cause and effect becoming indistinguishable. The use of a family systems approach in assessment and treatment has been shown to be valuable in these cases (Dare, 1992).

This issue contains papers presented at the 5 th Conference of Women and Mental Health. Scazufca and Kuipers look at the impact on women who care for those with schizophrenia. The article by Melvin and Sherr examines the psychological effects of HIV infection on families. They focus in particular on the effect of multiple loss and changes as well as on additional burdens of secrecy and guilt. It becomes clear that services providing care for women and children living with HIV need to focus on the family as a whole in order to serve their emotional as well as physical well-being. Feigenbaum considers the negative views that professionals often have of the non-abusing parent, and she promotes a focus on the whole family in assessment, treatment and research rather than an exclusive focus on victim and perpetrator. The issue of abuse is also addressed in the article by Gurr and Hansen. By means of a powerful account of personal experience, we see how an abused girl can turn into an abusing mother and how she can eventually break the vicious cycle.

Families are increasingly blamed when things go wrong, and held accountable both financially and emotionally when a member of the family becomes mentally ill. However, as professionals we tend to see the client, the patient, the 
offender, or perhaps the carer or dependants, but rarely consider the enormous benefit, with potential therapeutic gains, from considering the family as a whole.

\section{Acknowledgements}

We would like to acknowledge a considerable debt to Dr Molly Venning who helped in the planning of the 5th Conference on Women and Mental Health at the Institute of Psychiatry, which inspired these articles. Also, the help of Ms Lee Wilding, which enabled the smooth running of the conference.

\section{References}

DARE. C. (1992) Types of psychiatric treatment. Change the family. change the child? Archives of Disease in Childhood, 67, 643-648.

DuXBURY, L. E. \& HigGins, C. A. (1991) Gender differences in work-family conflict. Joumal of Applied Psychology. 76. 60-73.

EisenBerg. L. (1988) The soctal construction of mental illness. Psychological Medicine, 18, 1-9.

SuBotskY, F. (1991) Issues for women in the development of mental health services. Brttsh Joumal of Psychiatry 168. (suppl. 10), 17-21.

Henrikje Klasen, "Helen Crimlisk and Sarah Welch, Maudsley Hospital, Denmark Hill, London SE5 8AZ

"Correspondence 